Article

\title{
The Encounter with the Identical Other: The Literary Double as a Manifestation of Failure in Self-Constitution
}

\author{
Michal Tal \\ Department of Humanities and Arts, Technion-Israel Institute of Technology, Haifa 3448306, Israel; \\ michalt@tx.technion.ac.il; Tel.: +972-52-875-9961
}

Received: 28 September 2017; Accepted: 23 January 2018; Published: 29 January 2018

\begin{abstract}
Literary pieces featuring the double depict an encounter between the protagonist and another person, who is her identical other. Therefore they face various difficulties related to a threat cast on their unique identity, and this encounter challenges their process of self-definition. Martin Buber sees the existence of the other as essential for the occurrence of self-constitution within an individual. He maintains that any person needs another person to obtain confirmation of what she is and is born equipped with the ability to confirm her fellow-person in the same way (1959). However, as the other encountered by a doppelgänger protagonist is not truly "other", the latter might confront a difficulty in the different stages of Buber's self-constitution process. This paper seeks to shed light on the inter- and intra-personal relationships depicted in literary pieces focusing on the theme of the double, such as The Double (Dostoyevsky [1846] 1997; Saramago 2002), Despair (1965), and Too Much Nina (Orbach 2011), emphasizing the limitations cast by the encounter with the identical other on the protagonist's self-constitution, as put forward by Buber.
\end{abstract}

Keywords: self-constitution; doppelgänger; double; Buber; other; I-thou; genuine dialogue

\section{Introduction}

Doppelgänger literature deals with human identity and the fragile concept of the self by featuring protagonists whose self is radically challenged by the formation or appearance of another identical character, or by the splitting of the self into several independent elements. This phenomenon has been extensively studied from a psychoanalytic perspective (Rank 1971; Rogers 1970; Tymms 1999; among others). This paper seeks to show that studying it from a philosophical perspective, adopting Buber's theory of self-constitution by way of genuine dialogue, can throw a different light on this phenomenon, thus deepening the discussion of this intriguing experience. In particular, it may reveal why this phenomenon involves so much distress among the protagonists and perhaps shed light on why it is often perceived as captivating yet disconcerting for readers of this corpus of literary works.

Although this paper discusses the dynamics taking place between fictional characters, it does so as if they were real human beings. The assumption underlying this liberty is that duplicity, or self-split, are emotional experiences not entirely foreign - if not quite common-to human beings. To some extent, the incompleteness of selfhood exists and is sensed by anyone, and the sense of inner unity generally experienced by human beings is rather often delusionary (Dennett 1992; Bromberg 1998). Reading the doppelganger literature introduces us to extreme manifestations of this human phenomenon, thus allowing us to study it and analyze its significance more conveniently.

For Buber (1959, 1998a, 2002; Buber [1923] 1996), the existence of the other is essential for an individual's self-constitution to occur. He maintains that any person needs another person to obtain confirmation of what she is and is born equipped with the ability to confirm her fellow-person in the 
same way (Buber 1959). The course of self-constitution begins with positioning the other at a distance and continues with entering into a relationship with that other.

Literary pieces featuring the double depict an encounter between the protagonist and another person, who is his or her identical other. This is an "other" which is not truly "other". For this reason, the protagonists might confront a difficulty in one or both stages of Buber's self-constitution process. They might have difficulty positioning the other away from themselves. If they do manage to do so, they might enter a relationship with that other in a way which is not characterized by 'genuine encounter," that is, they may not be able to make their other present as a subject in itself. Instead, they tend to perceive the double as their own reflection. As a result, the encounter with the other does not assist them in acquiring an independent existence.

Buber differentiates between two types of inter-personal relationships: 'I-it', characterizing the relation of a person with an object which serves her needs; and 'I-thou', where one positions oneself across from another person and both make each other present. The protagonists of doppelgänger works often develop an 'I-it' relationship with their doubles, as they tend to make use of the other for their needs, hence naturally fail in entering a relationship aimed at making each other present. Neither party of the doppelgänger relationship views the other as possessing an independent existence, and rather than relating to the other as a particular person at a given moment, they see him as their own reflection. Therefore, they cannot be involved in a sincere "dialogue," as defined by Buber.

The positioning of the other at a distance means, according to Buber (1998a), the turning of the other into an independent opposition. This is a prerequisite for entering a relationship with the other. The basis for one's life with the other is double and single simultaneously-one's will to be confirmed of what she is, and even what she might be, on the one hand; and the innate ability to confirm the other in the same way, on the other hand.

The protagonists of doppelgänger literary works often fail in the basic movement needed to form a relationship with the other: they are not able to position the other at a distance, and instead merge with her or see her as their own reflection. Therefore, it is hardly surprising that most of them experience considerable difficulties in developing significant relationships with others. Moreover, not only do they not obtain confirmation of their existence as they are, but they also experience a constant threat and a deep turmoil as to who they are. Thus, for example, Herman, the protagonist of Despair (Nabokov [1965] 1989), completely fails in positioning Felix at a distance and cannot see the latter except as his own reflection despite the differences between the two. The tumult he experiences shortly after he meets Felix for the first time is expressed by the limpness, dizziness, and terrible fatigue he feels.

In a different way, Tertulliano, Saramago's protagonist in The Double (Saramago 2002) does not keep Claro, his double actor, at a distance at all. Rather, once he stumbles upon him accidentally while watching a video at home, he cannot help following his steps until he finds him and senses a critical threat to his authentic identity. In a way, Claro functions as an indication for what Tertuliano might be, as he asks himself what his life would look like if he were the actor. However, these thoughts do not provide the required confirmation of his existence, and the exemplary similarity between the two raises within him serious questions regarding the certainty of his independent existence.

The act of speaking, which Buber (1959) sees as the most typical characteristic of Man's life with the other, is based on the principle of the independent otherness of the other with whom one enters a relationship. It starts with acknowledging the other's otherness and continues with turning to the other on the basis of this acknowledgement. In order to constitute an interpersonal life this way, one needs to experience "genuine" encounters, where one perceives one's partiality and finiteness-hence one's need for the other's confirmation.

The protagonists of doppelgänger works frequently do not acknowledge the other's otherness, so their turning to this other does not enable a genuine encounter. Some do experience their partiality (e.g., the cloven viscount and Calvino's protagonist (Calvino [1952] 1998)). However, the presence of the other, who is not acknowledged as existing independently of the protagonist, does not provide 
confirmation of the existence of the latter. In fact, it deeply questions the very authentic existence of the protagonist. In other words, these protagonists are hardly capable of constituting inter-personal lives: they form an internal version of such a life with their doubles, which to a large extent remains intra-personal.

In an essay anthology titled The Knowledge of Man (Buber 1998a), Buber elaborates on the essence of a genuine encounter among people. Such an encounter culminates in an event named "making present": an individual stops perceiving the other as a component present in the world for his own service. Instead, one starts imagining what the other would ask for, feel, perceive, and think at a given moment. That is, one is capable of perceiving the living process in the other. Positioning the other at a distance and making her present positions the one involved in these actions at a distance as well and makes him independent too. The first movement of human life, thus, positions people in mutual existence, which is fundamental and of equal status. However, the second movement places them within a mutual relationship, which does not necessarily possess an equal character. The attitude is realized in complete "making present," when one thinks of the other not as this particular one, but experiences the sense of belonging to her as this particular one at a given moment. Only in this way can the other acquire a self of his/her own.

The protagonists of the doppelgänger literature are usually incapable of making their other present as a subject in herself: they perceive the other as their own reflection and hence do not obtain an independent existence as a result of this encounter. For instance, Herman (Nabokov [1965] 1989) shows no interest in Felix's subjectivity but consistently seeks what use he would be able to make of the latter to fulfill his own needs. Thus he does not "make him present" and naturally does not satisfy the conditions required for the mutual existence of the two as equal counterparts. Nor is Dostoyevsky's Golyadkin (Dostoyevsky [1846] 1997) capable of seeing his double present separately of himself. Though at times he feels inferior to his younger and more successful double, this momentary differentiation between himself and his double, which he seems to capture soon, turns into full identification or merging with his other.

\section{Doubleness as Failure to Establish a Dialogue}

Buber emphasizes the importance of a genuine encounter and relates to standing face-to-face with the other by way of mutual exposure as "a dialogue" (Buber [1965] 2002). The major requirement for the emergence of a genuine dialogue, maintains Buber, is that each of the participants relate to her other as what that other indeed is. One becomes aware of one's other, of the latter's being essentially different, in a unique way. One has to accept whom she sees that way. Even by struggling or arguing with that other, one confirms the other as the very creature standing opposite-and opposed to-her.

Kramer (2003) understands Buber's "dialogue" as one involving open, straightforward, mutual, and present communication between people speaking spontaneously, without inhibiting themselves nor promoting any agenda. He follows Buber's observations and mentions that Buber differentiates between three types of dialogue: "a genuine dialogue," whether spoken or silent, takes place when each of the participants indeed holds within herself the other as present in a particular way, and relates to that other in order to form a living mutual relation with him. Buber sees such a dialogue as a rare occasion.

Another type of dialogue, "a technical dialogue," occurs due to the urgent need for transient reciprocity, an objective understanding between people (as in cooperation between colleagues, or an accidental encounter between strangers where one asks the other for directions as to how to get to a certain place). However, Buber allows a genuine dialogue to occur abruptly even in the middle of a technical one.

The third type of dialogue is, in fact, a monologue disguised as a dialogue. The latter involves people talking in cunning ways, so that a certain speaker would like to form a certain impression on other people, or in a conversation between friends where emphasis is placed on the self more than on the interlocutor. 
Following Buber, Anderson and Cissna (2012) stress that a dialogue should not be confused with "social activity." A Buberian dialogue is not reached through the maintenance of many friendships, nor does it necessitate much talking. They quote Buber saying, "The life of dialogue life is not one in which you have much to do with men, but one in which you really have to do with those with whom you have to do." (Buber [1965] 2002, p. 20).

Anderson and Cissna attribute much significance to the spatial conceptualization of the Buberian dialogue, according to which the basic movement of a dialogic life is turning to the other. They claim that Buber refers to a situation where people turn to the other not only with their bodies, but also with their entire fundamental being, equipped with openness and reactiveness, as well as attentiveness to the other. Only under these conditions can a dialogic partnership thrive. It is important to note that, according to this conceptualization, a monologue is characterized not by withdrawal from the other, but by replication, a certain folding towards oneself, where instead of meeting the other in her particularity, the other exists only as part of the self. This situation turns the dialogue into a fiction, hence the chances for genuine inter-personal relationship significantly decline.

This observation summons an interesting perspective on what occurs during the encounter between the protagonist and his or her double in doppelgänger works. First, it should be spelled out that defining the type of dialogue developing between the two is not at all simple: at times, it is clear that the encounter between the two is very instrumental in nature, as the protagonist wishes to benefit from the extreme similarity to the double. A case in point is Herman, Nabokov's protagonist (Nabokov [1965] 1989), who sees in Felix an opportunity to escape from his own life. Seemingly, he has no interest in Felix himself, only in the benefit the latter's existence suggests. The relationship between Tertuliano and Claro, Saramago's protagonists (Saramago 2002), also have extremely practical aspects: it seems that each sees the other's life as an opportunity for a different destiny.

From a different angle, it is clear that a substantial part of the conversation taking place between the protagonist and the double exemplifies a monologue disguised as a dialogue: in a basic sense, this can be inferred from the very fact that rather than showing interest in the other, or in the one-time communication with the latter, the protagonists are all too often interested in talking about themselves. So does Golyadkin, for instance, who relates to his younger double his life story, and at some moments finds his double—-more than anything else—a good and understanding listener (Dostoyevsky [1846] 1997). In a deeper sense, the two can only generate a monologue, as the double is not really a different person, but a reflection of the protagonist. Thus, the developing dialogue is an internal one, taking place between different representations of one single self, which clearly does not express a genuine dialogue.

However, in spite of what has just been argued, and in a somewhat paradoxical manner, these pseudo-encounters may after all consist of moments endowed with elements of a genuine encounter. Following the night Golaydkin spends in the company of his younger image, the narrator states, "With tears in his eyes Mr. Golyadkin embraced his companion, and, completely overcome by his feelings, he began to initiate his friend into some of his own secrets and private affairs [ ... ]" (Dostoyevsky [1846] 1997, p. 54). These words seem to indicate a genuine encounter, and only the later clarification, revealing that the younger is but the protagonist's mental creation, presents this conversation as a monologue disguised as a dialogue. In other words, in retrospect, this intimate moment may be viewed as spurious, and forming a genuine dialogue between the two Golyadkins seems again like an impossible task.

Following Buber, Anderson and Cissna point to three problems hindering dialogic life: the intrusion of "seeming," the inadequacy of inter-personal perception, and the tendency to influence others by imposing one's opinion on them. The duality of being and seeming is "the essential problem of the sphere of the interhuman" (Buber [1965] 2002, p. 75), according to Buber. "Being" refers to what a person really is, whereas "seeming" refers to what he would like to reveal to others, or how one would like to seem to others. Clearly, no one lives solely in one of these states, but one state is often dominant. Buber believes that, in the inter-personal sphere, "truth" means that people communicate themselves to each other as what they really are. This does not necessitate telling each other everything, 
but forbidding any falsehood to come between them. For that purpose, the speaker must promise her interlocutor a piece of her being. Golyadkin, yearning for a significant relationship, does share with his young friend "pieces of his being," so much that he feels completely bare before him. However, other doppelgänger protagonists tend to protect themselves from their double and present a false appearance, as the presence of the latter makes them experience a threat to their unique existence.

The second threat posed to dialogic life has to do with perceiving people as they are. For a genuine dialogue to develop, each of its participants should relate to the other as they really are. Being aware of the other in this way entails perception and understanding of the other as a whole person, out of complete willingness to imagine the "dynamic center" characterizing each utterance, action, and attitude of the other.

Buber names this willingness "inclusion" or "experiencing the other side" (Buber [1965] 2002). If the other does not react in a similar way, then the dialogue might die quickly. Yet if reciprocity occurs, then the inter-personal blooms into a genuine dialogue. In literary pieces featuring the double, most protagonists do not perceive the other as a whole person. In fact, they tend to perceive themselves as partial vis-à-vis the other. This is epitomized in works where the protagonists express a need for the existence of their identical-other in order to sense their existential wholeness. In the Israeli novel Too Much Nina (Orbach 2011), Miki, the protagonist's closest friend, says that knowing she had a twin sister from whom she had been separated at birth, Nina had been feeling like half-a-person during her whole life. This sensation indeed accompanies Nina throughout the novel, and does not seem to cease even when she finally meets Clara, her twin sister.

In a more extreme way, the two halves of the viscount, Calvino's protagonist (Calvino [1952] 1998), stand face to face when their existential partiality is most tangibly present. They also address and respond to the others this way, as well as to their other half. According to Buberian criteria, this situation does not enable the establishment of any genuine dialogue, by definition. We can also infer that these circumstances do not allow any inter-personal sphere to come into being: whatever takes place occurs within an intra-personal sphere.

The third threat to dialogic life concerns two distinct ways of affecting another person: imposing and unfolding. Anderson and Cissna (2012) note that Buber associates imposing with propaganda initiated by a person devoid of any genuine interest in others, who is unaware of the real existence of the other and only wishes to impose her opinion on the latter. By contrast, the genuine educator acts in order to facilitate the development of forces existing within the other, which are about to materialize. Both the propagandist and the educator are interested in influencing the other, but unlike the propagandist, the educator takes the other into consideration, in her entirety and uniqueness and wishes to help in developing the latter's potential.

The approach held by the protagonists of doppelgänger works tends toward imposing rather than toward unfolding. Such an approach is exemplified in William Wilson's (Poe [1839] 1976) description of his classmate who bears his name. He feels that his double resembles himself so much in his abilities that he is his superior. The competition between Wilson and his double arouses within the protagonist hostility towards the latter. His opponent, who knows him intimately, is depicted as patronizing him. These manifestations reflect the unequal relations existing between the two.

In a slightly different way, one can observe Herman's tyrannical attitude towards Felix, in Nabokov's Despair (Nabokov [1965] 1989). Herman describes Felix's appearance as repugnant, pities him, and gives him money in order to allow him the satisfaction of his basic needs. Thus, he cares for him in a patronizing way. If this leaves any doubt regarding the inability to form a genuine dialogue under these circumstances, then Herman himself, self-humoredly, confesses summoning Felix for a "monologue." In other words, he does not even pretend to engage in a dialogue with Felix.

Another significant element in Buber's perception of communication emphasized by Anderson and Cissna (2012) involves "confirmation." People practically confirm each other according to their personal qualities and capabilities. For Buber, a society is as humane as the extent to which its members confirm each other. Confirmation involves accepting and recognizing the other, both as the latter is 
and as what she might become. Confirmation may also involve a conflict, where a person sticks to her opinion and still tries to listen to the other real person with whom she converses. Two people may confirm each other by way of conflict as well.

Literary doubles often fail in confirming each other. As a matter of fact, their simultaneous presence threatens the existence of each as a unique individual. Even the explicit conflict between the two cannot calm them down as far as their authentic existence is concerned. This failure, along with the wish for confirmation, is central in several of the doppelgänger works. Following a night of intimate closeness with his double, Golyadkin meets the latter at work and depicts his feelings as follows:

Recognizing in a flash that he was ruined, in a sense annihilated, that he had disgraced himself and sullied his reputation, that he had been turned into ridicule and treated with contempt in the presence of spectators, that he had been treacherously insulted, by one whom he had looked on only the day before as his greatest and most trustworthy friend, that he had been put to utter confusion, Mr. Golyadkin senior rushed in pursuit of his enemy.

(Dostoyevsky [1846] 1997, p. 65)

Saramago's novel, The Double (Saramago 2002), also abounds in indications of Teruliano's yearning for confirming his own existence. For instance, shortly before his encounter with Claro and their comparison of ages, the narrator mentions, "Tertuliano Máximo Afonso is troubled now by the possibility that he might be the younger of the two, that the other man might be the original and he nothing but a mere and, of course, devalued repetition." (Saramago 2002, p. 175).

Anderson and Cisna conclude by listing three characteristic signs of Buber's dialogic communication. First, Buber's communication philosophy encourages genuineness or authenticity, which does not entail complete exposure yet reprimands pretension, exclusive self-attention, and renunciation of the inter-personal sphere. Secondly, Buber emphasizes the importance of being aware of others as unique and whole people, an attitude that enhances turning to the other, attempting to imagine the other's reality, accepting the other as a partner, hence confirming the other as a human being. Thirdly, in authentic relations a person can struggle decisively in order to influence the other, but being open to change by others, this struggle will never amount to hurting the other. Dialogue is not perceived as a tool for manipulating the other, though persuasion often does take place in this sphere. A dialogue relies on respect and willingness held by both partners, enabling mutual reality and ability for opening rather than coercion of ideas in a monologic manner. Anderson and Cisna conclude that, for Buber, human experience consists of both the quest for unity and the search for individuation.

As has been said, most of the doppelgänger protagonists do not fulfill consistently any of the dialogical communication signs put forward by Buber. They are not able to perceive others as different from themselves and unique. For them, their doppelgänger others are but a variation of themselves. Therefore, they do not confirm the other's distinct existence, let alone are confirmed by that of the other. The struggle they are immersed in often does not leave any space for difference between the two, as expected by Buber, a space which could have come back to them as confirmation of their own identity. Since they pose their own images in front of themselves, images they are not willing to perceive as distinct, there exists no space for dialogue. Nevertheless, it is interesting to note that these protagonists too-and perhaps in an especially clear way-also embody the human experience of looking for unity with the other, verging on merging, side by side with the quest for individuation, differentiation, and uniqueness vis-a-vis the other.

In his book I and Thou (Buber [1923] 1996), Buber differentiates between two types of relation patterns: 'I-it', where a person is introduced to an object, with which she experiments and of which she makes use, on the one hand; and 'I-thou', where a person stands across from another person, whom the former makes present by her confirmation, and thus is also made present as an independent entity. According to Buber, while in the 'I-it' pair the 'I' appears as an individuality which becomes aware of itself as a subject experimenting and using the object, in the 'I-thou' pair the 'I' appears 
as a person and becomes aware of herself as a subjectivity. Individuality appears as being distinct from other individualities, whereas a person appears by entering a relationship with other persons. Thus, for Buber, personhood and individuality stand in two contrastive poles, where individuality shares no reality with the other but distinguishes itself from the other and requests to appropriate to itself as much as possible by way of experience and use. This way it acts on an object rather than on another person (Wyschogrod 1967).

As a rule, protagonists of the doppelgänger works tend to develop an I-it relation with their double: it seems that rather than appearing as persons aware of themselves as subjectivities, they make use of the other for their own needs, avoiding any relation of mutual making-present. This has been illustrated regarding Herman in Nabokov's Despair (Nabokov [1965] 1989). As for Buber's distinction between an "individual" and a "person," it seems that these protagonists do not gain any of these qualities: on the one hand, they are not clearly distinct from other individuals, but tend to merge with them. On the other hand, they do not form relations with other people as different to themselves. Indeed, rather than sharing their experiences with their others, they keep struggling for their distinct existence.

The process aimed at reciprocal making-present may also end in failure. Buber maintains that if a person does not attempt to achieve and actualize her essential "thou" with regard to what she encounters, then she withdraws inwards and develops in a space that does not offer her any real room for development. Hence, confrontation with what stands in front of her occurs within herself, and this cannot constitute a relation, or presence, or flowing interaction, but only self-contradiction.

Buber advocates that the affinity to the other comes first. Hugo Bergman, in his preface to the Hebrew edition of $I$ and Thou, annotates that "a person becomes an ' $\mathrm{I}$ ' with the help of the 'thou.' This thou goes out, and another one comes instead, and with the changes of these 'I's, the constant 'I' consolidates in its affinities, until the 'I' finds itself vis-à-vis itself as a separate 'I,' or the I-thou affinity breaks down and the 'I' leaves its 'thou' and stands vis-à-vis itself alone." (Buber 1959, p. 17, my translation). That last option is the one indicating the failure in the double move towards subjectivity put forward by Buber.

In the doppelgänger literature, one may point to similar dynamics to the one mentioned by Buber. In some cases, the protagonist and the double do try to make each other present, motivated by the will to become independent. This is the case, for instance, with the encounter between Nina and her twin, Clara (Orbach 2011), where each twin seems to hold that by making her twin present she will perfect something missing in her own life and acquire a status of independent wholeness. Nevertheless, finally they do not succeed in realizing a parallel whole existence of each and keep instead to their partial existence following their mutually decided role reversal.

By contrast, there are other cases where at least one of the parties relates to its other instrumentally, and does not see the other as "thou," but as a kind of "it." A case in point is Felix (Nabokov [1965] 1989), whose only role for Herman serves as a substitute on his fabricated suicide. Similarly, the narrator in "The Shadow" (Andersen [1847] 1946) makes instrumental use of his shadow in order to realize desires he cannot fulfill on his own. Later on in the story, the two switch roles, and the shadow-who has acquired his own identity by now-is the one to make use of the author, whose very projection he used to be.

At times, the attempt at reciprocal making-present fails, and at least one of these figure withdraws into themselves into self-contradiction and in fact does not maintain any "relation", i.e., does not move forward to the second movement in human life. Dostoyevsky's Golyadkin illustrates the inability of the individual experiencing doubleness to turn out to the other and make him present. Indeed, he ends up completely withdrawn from others (Dostoyevsky [1846] 1997).

Charme (1977) notes that I-thou relations are discussed by Buber across two contradictory parallel levels: the epistemological and the ethical. At the epistemological level, Buber deals with man's relation with God and the modes in which she can get to know God. Buber aims to show that man's relation to God is personal, as she can only know God the way she knows the other, where God is 
perceived as the absolute other. As we cannot possibly validate our knowledge about God objectively, this knowledge - as the knowledge about any Thou-is of unique nature: it is intuitively self-validated, undefinable, momentary and devoid of any content. Charme describes it as mystical knowledge, which negates any ordinary way of knowing about a person or an object. The 'I-thou' encounter is thus immediate and timeless. For the ' $\mathrm{I}$ ', the Thou is not a specific entity in space and time; rather, the 'I-thou' relations take place in a present devoid of time and space.

In such an encounter, a person meets a Thou who is a unique indivisible unity. The encounter takes place with the object-as-is, about whom there is no specific knowledge or sensory perception. No use is made of cognitive categories for the purpose of knowing this Thou. Though this is an encounter devoid of experience, sensory data, and content regarding the Thou, the individual does obtain an absolute kind of knowledge, which is undoubtable despite its being incomprehensible. For this reason, it cannot be mistaken either.

Buber identifies "experience" with the realm of the "it," as this is the way the world is mediated to us by means of one's senses and intellect. Buber finds experience to be superficial, since it deals only with appearance (or "seeming") and misses the real being of people and things. For him, experience is but an accumulation of information that does not genuinely involve the world, because it arises within a person rather than between one and the world.

According to Charme, a relation that is the result of the unmediated and mystical encounter between the 'I' and the 'Thou' does not necessitate any sounds, gestures, or words. A sudden silent communication may occur between two people who do not talk to each other, look at each other, or know anything about one another. Charme notes that this type of encounter, occurring beyond actual encounter between people, might pose difficulties to keeping the individuality of the ' $\mathrm{I}$ ' and Thou and the distinction between the self and the other.

This perspective regarding Buber's 'I-Thou'" concept is particularly interesting in the context of the doppelgänger works, as the encounter between the protagonist and her double is often mystical and frequently experienced supersensually. This is apparent in Saramago's The Double (Saramago 2002): having watched the video where he sees his cinematic double for the first time, Tertuliano goes to bed. Soon after, he wakes up feeling that another person is present at his home: "The sense of another presence that had woken him up grew slightly stronger." (Saramago 2002, p. 14). Ricardo Reis's encounters with the late poet Pessoa are also irregular, having nothing to do with actual presence or ordinary sensual and cognitive recognition (Saramago [1984] 1999). Their first encounter, for example, is described as follows: "[ . . ] there was a man sitting on the sofa. He recognized him at once, though they hadn't seen each other for many years. Nor did he think it strange Fernando Pessoa should be sitting there waiting for him." (Saramago [1984] 1999, pp. 64-65). If it seems that the protagonist only imagines Pessoa's visit, a few days later the narrator mentions that, "Ricardo Reis did not ask himself the obvious question, Could it have been a dream, he knew that Fernando Pessoa, with enough flesh and bone to embrace and be embraced, had been in this very room [ . . . ]" (Saramago [1984] 1999, p. 69). Pessoa's presence is therefore undoubtable, though it is not perceived via regular sensory means.

Indeed, as Charme cautions, such an encounter poses difficulties in keeping one's individuality for both partners involved in doubleness, as well as in the distinction between the two. Terulilano, for instance, is cast into uncertainty regarding his identity from the very moment he encounters Claro for the first time (Saramago 2002). Similarly, Reis attempts to "clothe his own portrait with a new substance, to be able to raise his hands to his face and recognize himself [ . . ]" (Saramago [1984] 1999, p. 69), following the encounter with Pessoa.

At the ethical level, Buber advocates the 'I-Thou' relations as the appropriate way of treating other people, out of respect for any individual's wholeness and uniqueness. The main prerequisite for a genuine dialogic situation is treating the other as she is and becoming aware of her being essentially different to me, in an absolute and unique way, sincerely accepting this different being. Charme emphasizes that Buber strongly urges people to avoid the use of another person, such that no 
purpose, desire or expectation be involved between the 'I' and the 'Thou', thus no harm be caused to the encounter.

From this perspective, one may claim, almost sweepingly, that the doppelgänger protagonists do not fulfill the ethical requirements put forward by Buber in order to generate a genuine dialogue. They tend to treat their double instrumentally for the realization of their own needs, as has been suggested, and see the other only in her partiality. Above all, they do not respect the other's otherness and usually manage to see her only as their own image.

Charme concludes his paper stating that the analogy made by Buber between relations with the other and relations with God is based on a superior way of knowing, devoid of content and unconfirmable. However, the 'I-Thou' relations are presented from an ethical point of view as well, which does not agree with the epistemological one. Charme advocates that Buber's 'I-Thou' philosophy would be best treated if each of the aspects of this relation - the epistemological and the ethical-were evaluated separately. In view of what has already been mentioned, the doppelgänger situation may provide a unique opportunity to examine each aspect individually.

Following Buber, Wood (1969) and Kramer (2003) define the central characteristics of 'I-thou' relations, which include totality, merging of will and grace, immediacy, and reciprocity. Totality refers to indiscernible merging of characteristics. The perceived 'Thou' is not the total sum of the elements involved in the encounter, but a quality existing beyond them and serving as their source of unity. The knowledge held by one about one's other in an 'I-Thou' relation is seen by Wood as equivalent to the way Adam knew Eve, seeing the wholeness by way of knowing the other's uniqueness.

A merging of will and grace refers to turning into a person who can indulge in relation, that is, one who imagines the other in an actual way and is able to include the other. Further on, in order for a person to give oneself to the other, a measure of grace is needed. This is not about an active attitude of giving, nor is it about passivity. Rather, it refers to a merging of the two, so that an individual's activities are sustained, yet the major act of the individual's being is executed by one's mere saying "thou." Offering oneself to a "thou" entails a similar offer put forward by that other. Only by this reciprocal offer is the completeness attributed by Buber to the 'I-Thou' encounter achieved.

Wood suggests that Buber requires the individual not to reduce the past of the other, or embed the other in one's well-organized experience of objects. Instead, in immediacy, one should identify the uniqueness and momentariness of the encounter with that particular individual who stands before her, out of wonder. Only this immediate attitude will allow for the emergence of 'I-Thou' relations. Even though the appearance of the double before the protagonist is often accompanied by wonder mixed with terror, and, despite the fact that this appearance is seen as unique, it seems that the double is soon integrated into the protagonist's familiar course of life and is expected to fulfill some function in that context.

The will for encounter active on both parties yields reciprocity, such that one individual affects the other as the other affects the former. According to Wood, Buber does not refer to "effect" as the feeling arising within an individual, as this is a psychological phenomenon occurring within oneself. Rather, the location of the effect is the intermediate area between two people who are involved in the encounter. He sees love as the supreme manifestation of the intermediate (between) area, which expresses primarily reciprocal authentic responsibility. Nevertheless, he emphasizes that in its authentic sense, love is the realization of a relation, and hence it presumes the totality of view, i.e., seeing everything. As far as love does not see everything, as far as it is blind, love is not indeed love. Thus it is not an authentic form of dialogue but one form or another of monologue, where the other is the image of the individual's self-interest. In the doppelgänger narrative, it often seems that the protagonist views her double partially and focuses her vision on the parts seemingly lacking in herself. In Mark Twain's The Prince and the Pauper (Twain [1881] 1996), for example, Tom sees in Edward mainly the latter's genuine princedom, which he lacks in great amounts. Similarly, in Jean Stafford's "The Echo and the Nemesis" (Stafford [1950] 1993), Ramona sees in Martha the beauty which was once hers but is not so anymore. In these cases, the double is nothing but an object fulfilling the protagonist's interest. 
In other words, the doppelgänger narratives are frequently devoid of all four characteristics of the 'I-Thou' relation, a fundamental position which cannot yield any genuine Buberian dialogue between the two.

\section{The Lack of the Between Sphere as the Failure Underlying Doubleness}

In his essay titled "The Word that Is Spoken" (Buber 1998b), Buber emphasizes the importance of spoken language, which does not want to remain with the speaker but "reaches out toward a hearer [... ] it lays hold of him [ . . and] even makes the hearer into a speaker" (Buber 1998b, p. 354). Buber clarifies that the place of occurrence of language is not the total sum of the participants involved in the dialogue, but the space between them ("the between"). This space always leaves traces in the discourse partners. The dialogue, according to Buber, consists exactly in that which does not belong to any of the participants, nor does it pertain to the choice of words exchanged between them, but to "spokenness" itself.

Friedman (1976) stresses that Buber differentiates in his essay between truth regarding the reality, which has been perceived and now is expressed, truth regarding the person one turns to and makes-present, and truth regarding the speaker's factual existence. This human truth, he claims, opens itself only in the presence of that individual as this concrete individual, who responds genuinely to the word spoken by the former individual.

This description of the essence of dialogueness may clarify the failure underlying doubleness in its literary manifestation: the doubles do not view each other as possessing an independent existence, and rather than treating the other as a particular person at a given moment, they see each other as their own image and do not become involved in a genuine dialogue with each other. This stems from the fact that no in-between sphere emerges between the two, since their merging does not allow the emergence of such a space. In fact, their relation does not leave any space at all.

In conclusion, Buber advocates the inherent need for doubleness by way of mutual making-present in order for a subjective independent self-constitution to occur. However, doubleness which constitutes identity, and which does not recognize the otherness of the "thou," annihilates the between sphere and does not allow any genuine dialogue to occur. Thus, the protagonists of works featuring the double cannot indulge in self-constitution. This may illuminate the severe sense of distress involved in most of these. As such, Buber's theory of self-constitution by way of genuine dialogue may offer another angle for examining what occurs within the protagonists of this literary corpus and why it arouses such intrigue and discomfort among its readers.

Conflicts of Interest: The author declares no conflict of interest.

\section{References}

Andersen, Hans C. 1946. The Shadow. In Fairy Tales. Cleveland: World. First published 1847.

Anderson, Rob, and Kenneth N. Cissna. 2012. Martin Buber: Bearing Witness to an Experience. In Philosophical Profiles in the Theory of Communication. Edited by Jason Hannan. New York: Peter Lang, pp. 127-58.

Bromberg, Phillip. 1998. Standing in the Spaces: Essays on Clinical Process, Trauma, and Dissociation. Hillsdale: Analytic Press.

Buber, Martin. 1996. I and Thou. Translated by Walter Kaufmann. New York: Simon and Schuster. First published 1923.

Buber, Martin. 2002. Between Man and Man. Translated by Ronald Gregor-Smith. New York: Routledge. First published 1965.

Buber, Martin. 1959. The Dialogue on Man and Being. Philosophical Writings; Translated by Hugo Bergman. Jerusalem: Bialik Institute, vol. 1, pp. xi-xlvi.

Buber, Martin. 1998a. The Knowledge of Man: Selected Essays. Translated by Maurice Friedman, and Ronald Gregor-Smith. Amherst: Prometheus Books.

Buber, Martin. 1998b. The Word That Is Spoken. In The Knowledge of Man: Selected Essays. Translated by Maurice Friedman, and Ronald Gregor-Smith. Amherst: Prometheus Books.

Calvino, Italo. 1998. The Cloven Viscount. In Our Ancestors. London: Vintage, pp. 1-73. First published 1952. 
Charme, Stuart. 1977. The Two I-Thou Relations in Martin Buber's Philosophy. Harvard Theological Review $70:$ 161-73. [CrossRef]

Dennett, Daniel. 1992. The Self as the Center of Narrative Gravity. In Self and Consciousness: Multiple Perspectives. Edited by Frank S. Kessel, Pamela M. Cole and Dale L. Johnson. Hillsdale: Erlbaum, pp. 103-15.

Dostoyevsky, Fyodor. 1997. The Double. Dover: Thrift Editions. First published 1846.

Friedman, Maurice Stanley. 1976. Martin Buber: The Life of a Dialogue. Chicago: University of Chicago Press.

Kramer, Kenneth Paul. 2003. Martin Buber's 'I and Thou': Practicing Living Dialogue. Mahwah: Paulist Press.

Nabokov, Vladimir. 1989. Despair, kindle ed. New York: (Vintage International) Knopf Doubleday Publishing Group. First published 1965.

Orbach, Dalit. 2011. Too Much Nina [Yoter Mida'i Nina]. Tel-Aviv: Miskal.

Poe, Edgar A. 1976. William Wilson. In The Short Fiction of Edgar Allan Poe. Indianapolis: Bobbs-Merrill, pp. 271-83. First published 1839.

Rank, Otto. 1971. The Double: A Psychoanalytic Study. Harry Tucker, trans. and ed. Chapel Hill: University of North Carolina Press.

Rogers, Robert. 1970. A Psychoanalytic Study of the Double in Literature. Dertoit: Wayne State University Press.

Saramago, José. 1999. The Year of the Death of Ricardo Reis. Translated by Giovanni Pontiero. London: Harvil Press, First published 1984.

Saramago, José. 2002. The Double, kindle ed. Translated by Margaret Jull Costa. New York: Houghton Mifflin Harcourt. Stafford, Jean. 1993. The Echo and the Nemesis. In The Collected Stories of Jean Stafford. Austin: University of Texas Press, pp. 35-53. First published 1950.

Twain, Mark. 1996. The Prince and the Pauper. New York: Oxford University Press. First published 1881.

Tymms, Ralph. 1999. Doubles in Literary Psychology. Ann Arbor: UMI Books.

Wood, Robert E. 1969. Martin Buber's Ontology: An Analysis of 'I and Thou'. Evanston: Northwestern University Press. Wyschogrod, Michael. 1967. Martin Buber. In Encyclopedia of Philosophy. Edited by Paul Edwards. New York: Macmillan, vol. 1, pp. 409-11.

(C) 2018 by the author. Licensee MDPI, Basel, Switzerland. This article is an open access article distributed under the terms and conditions of the Creative Commons Attribution (CC BY) license (http:/ / creativecommons.org/licenses/by/4.0/). 